\title{
Cultural selection and human food preferences
}

\author{
Ani Bajrami \\ Research Center for Flora and Fauna, Faculty of Natural Sciences, University of Tirana, Tirana, Albania
}

\begin{abstract}
Genes and culture co-evolve to determine variations in dietary habits. Our evolutionary heritage regarding food choice and food preferences is responsible for the mismatch with the food environments we have created, which leads to problems such as overweight and obesity. Several hypotheses have attempted to explain the high rate of obesity present in today's world. The thrifty genotype hypothesis suggested that obesity today is a throwback to our ancestors having undergone positive selection for genes that favored energy storage. The drifty genotype hypothesis contends that the prevalence of thrifty genes is not a result of positive selection for energy-storage genes but, rather, is attributable to genetic drift resulting from the removal of predatory selection pressures. Both hypotheses focus on environmental changes over time, positive selection and genetic drift. While genetics plays a significant role, we believe that cultural selection is also responsible for the spread of obesogenic phenomena in Albania. The high rates of overweight and obesity among Albanians today can be explained as a mismatch between our evolutionary past and maladaptive behaviors.
\end{abstract}

Correspondence: Ani Bajrami, Research Center for Flora and Fauna, Faculty of Natural Sciences, University of Tirana, Bulevardi Zogu I, Tirana, Albania.

E-mail: ani.bajrami@fshn.edu.al

Key words: Cultural selection; Human food preference; Obesity; Overweight; Albania.

Conflict of interest: the author declares no potential conflict of interest.

Funding: University of Tirana, Albania

Conference presentation: part of this paper was presented at the National SIBS Congress, Trapani, Italy, 27-28 October 2017.

Received for publication: 16 June 2018 .

Accepted for publication: 6 August 2018.

(C) Copyright A. Bajrami, 2019

Licensee PAGEPress, Italy

Journal of Biological Research 2019; $92: 7641$

doi:10.4081/jbr.2019.7641

This article is distributed under the terms of the Creative Commons Attribution Noncommercial License (by-nc 4.0) which permits any noncommercial use, distribution, and reproduction in any medium, provided the original author(s) and source are credited.

\section{Introduction}

Changes in diet afforded by cultural practices, such as agriculture and the domestication of plants and animals, provide compelling examples of gene-culture co-evolution, demonstrating how cultural practices have transformed the selection pressures acting on humans and giving rise to some genetic differences between human populations. ${ }^{1}$ Lactose tolerant human society is an example of a gene-culture co-evolution between cattle and humans ${ }^{2}$ when primary lactose malabsorption is an inherited deficit present in the majority of the world's population. ${ }^{3}$ Furthermore, eating habits, living environments and metabolic levels in different races can influence the characteristics of the gut microbiome. ${ }^{4}$ Most importantly, cultural and genetic evolution can interact with one another and influence both transmission and selection. ${ }^{5}$ Environmental conditions trigger social groups to respond in different ways which are manifested in their behaviors. The concept of evoked culture, first proposed by Tooby and Cosmides (1992) refers to phenomena that are triggered in some groups more than in others because of differing environmental conditions. ${ }^{6}$ For example, the evolutionist Elizabeth Cashdan (1989) found that some San groups are more egalitarian than others and that these cultural differences are closely linked with the variance in food supply. ${ }^{7}$ Food sharing is conditioned by food abundance in a certain environment. When food variance is low, a social group tends not to share it outside their extended family. Cultural differences regarding consumption behaviors can be attributed to the evoked culture and transmitted culture. Much of an individual's behavior is a product of beliefs, skills, ethical norms and social attitudes that are required from others with little, if any, modifications. ${ }^{8}$ Culture refers to representations or ideas that originally existed in at least one mind and are transferred to other minds through observations or interaction. ${ }^{6}$ Humans are generalist feeders. The basic physiology and morphology of Homo sapiens sets boundaries to our eating habits, but within these boundaries human food preferences are remarkably varied, both within and between populations. ${ }^{9}$ Cultures have developed elaborate ways of selecting and preparing food which has to do with one of the basic domains of survival. ${ }^{10}$ As mentioned, the selection of food depends on the environment a certain society lives and more importantly, it is deeply influenced by the culture or the learning and transmission of behaviors. The ways in which humans classify and reason about the organic world it is called folk biology. ${ }^{11}$ Changes in food choices and food preferences within any culture usually take place over decades or even centuries. Multiple microevolutionary processes may lead to a dissemination of traits that are not necessarily advantageous. ${ }^{12}$ Furthermore, major and rapid cultural changes influence food choice and preferences and are responsible for a mismatch with our evolutionary past leading to an obesity epidemic in today's members of society around the world. 


\section{The overweight and obesity epidemic}

Overweight is defined as having excess body weight for a particular height from fat, muscle, bone, water, or a combination of these factors. ${ }^{13}$ Obesity is defined as having excess body fat. ${ }^{14}$ The reasons for the differences in the prevalence of obesity among groups are complex, likely involving genetics, physiology, socioeconomic status, environment and interactions among these variables, as well as others that have not yet been fully recognized. ${ }^{15}$ Several hypotheses have attempted to explain the high rate of obesity present in today's world. In 1962, the geneticist James Neel proposed the thrifty genotype hypothesis, which suggested that obesity today is a throwback to our ancestors having undergone positive selection for genes that favored energy storage as a consequence of the cyclical episodes of famine and surplus after the advent of farming 10,000 years ago. ${ }^{16}$ Since famine never arises out of an abundance of food, there is a mismatch between the environment in which the brain evolved and the environment of today. This mismatch results in the high prevalence of obesity rates worldwide and health problems such as diabetes. ${ }^{16}$ This assertion is in line with the adaptive lag notion. Adaptive lag refers to a mismatch between humans and their current environments. ${ }^{17}$ Human minds are organized into a large number of evolved psychological mechanisms in order to solve recurrent problems faced by our hunter-gatherer ancestors and are unable to respond quickly to selection.6,18 The Environment of Evolutionary Adaptedness (EEA) is a concept which states that our psychological mechanisms have evolved in response to stable features of ancestral environments. ${ }^{19}$ When combined with the concept of the EEA, gradualism suggests that human beings experience an adaptive lag. ${ }^{20}$ In this context, there exist maladaptive perceptions and cultural practices regarding food choice. But the view that a universal genetic program underpins human cognition is not fully consistent with current genetic evidence ${ }^{1}$ and the modifications of the environment by humans. ${ }^{21}$ The prevalence of obesity in modern societies has two major contributory factors: an environmental change that has occurred historically and a genetic predisposition that has its origins in our evolutionary history. ${ }^{22}$ The drifty genotype hypothesis contends that the prevalence of thrifty genes is not a result of positive selection for energy-storage genes but, rather, is attributable to genetic drift resulting from the removal of predatory selection pressures. ${ }^{23}$ This hypothesis has been challenged, and genetic drift is not viewed as a main factor in causing obesity. A combination of famines and seasonal food shortages in the post-agricultural era has exerted natural selection in favor of fat storage. ${ }^{24}$ Another hypothesis contends that the modern obesity pandemic in industrialized countries is a result of the differential exposure of the ancestors of modern humans to environmental factors that began when modern humans left Africa around 70,000 years ago and migrated throughout the globe, reaching the Americas around 20,000 years ago. ${ }^{25}$ The last hypothesis considers the context of historic human population redistribution and ethnic differences in genetic susceptibility to obesity and the metabolic syndrome. All three mentioned hypotheses focus on environmental changes over time, positive selection and genetic drift, and human population redistribution. The last hypothesis considers the context of historic human population redistribution and ethnic differences in genetic susceptibility to obesity and the metabolic syndrome. All three mentioned hypotheses focus on environmental changes over time, positive selection and genetic drift, and human population redistribution. On the other hand, the behavioral switch hypothesis explains the modern pandemic of metabolic diseases as caused by extreme environmental stimuli: population density, urbanization, social competition, access to high-calorie foods, and sedentary lifestyles exaggerated to an extent never before witnessed in human history. ${ }^{26}$ This hypothesis argues that metabolic diseases are by-products of a socio-ecological adaptation that allows humans to switch between both reproductive and socio-behavioral strategies, and maintains that physiological responses that were adaptive in the past have become maladaptive in modern environments. ${ }^{27}$

\section{Consumption behaviors regarding health and food in Albania}

Traditionally, Albanian diet has been characterized by a low consumption of total energy, meat, and dairy products, but a high consumption of fruit, vegetables, and carbohydrates. ${ }^{28}$ However, after the breakdown of the communist regime in early 1990s, Albania has undergone a rapid transition including dietary changes. ${ }^{29}$ In adult population, post communisms major dietary changes have been reflected in health ${ }^{30,31}$ and even higher mortality rates in comparison to Western Europe. ${ }^{32}$ Socioeconomic factors also influence the rates of obesity. ${ }^{33}$ Obesity is a social phenomenon, for which appropriate action includes targeting both economic and socio-cultural factors. ${ }^{34}$ In addition, the built environment has been thought to play an important role in influencing obesity by creating a climate that promotes increased energy consumption and a reduction in energy expenditure ${ }^{35}$ with the term built environment encompassing aspects of a person's surroundings which are human-made or modified, as compared with naturally occurring aspects of the environment. ${ }^{36}$ A nationwide survey conducted in Albania in 2013 comprising a representative sample of 5810 schoolchildren aged 7.0-9.9 years, indicated that $9.8 \%$ of the boys were obese $v s 5.5 \%$ of the girls indicated that the prevalence of both overweight and obesity was remarkably higher among urban children than among their rural counterparts. ${ }^{37}$ Over half's of the world population (54\%) currently lives in urban areas. ${ }^{38}$ People living in urban center are more familiar with brand foods and develop poor dietary habits compared with their rural counterparts, who tend to value traditional food more. Furthermore, those living in areas with the lowest and highest and shares of green space have the highest probability of being obese. ${ }^{39}$ Most importantly, contact with nature in general and contact with urban green more specific, have the potential to positively contribute to human health and well-being. ${ }^{40,41}$

\section{Conclusions}

Cultural and genetic evolution can interact with one another and influence both modes of transmission and selection. Human food choice and preferences are not only genetically determined but are learned through different modes of transmission which can be maladaptive in nature. Additionally, after a long cultural isolation, a major and rapid cultural transition affecting a certain population creates different preferences and choices in relation to food. In Albania, post-communist period was accompanied by the spread of different brand foods and made possible an array of preferences regarding food consumption. Changes in dietary habits and lifestyles as a result of rapid economic, social and urban changes were formed. Beside the creation of new food choices and food preferences from pre-existing norms in relation to food, cultural selection is responsible for creating a series of maladaptive behav- 
iours in relation to food. The mismatch between our evolutionary past alongside maladaptive behaviours as a result of cultural selection explain the high rates of overweight and obesity among Albanians today.

\section{References}

1. Bolhuis JJ, Brown GR, Richardson RC, Laland KN. Darwin in mind: new opportunities for evolutionary psychology. PloS Biol 2011;9:e1001109.

2. Beja-Pereira A, Luikart G, England PR, et al. Gene-culture coevolution between cattle milk protein genes and human lactase genes. Nat Genet 2003;35:311-3.

3. Perino A, Cabras S, Obinu D, Cavalli Sforza L. Lactose intolerance: a non allergic disorder often managed by allergologist. Eur Ann Allergy Clin Immunol 2009;41:3-16.

4. Chen L, Zhang YH, Huang T, Cai YD. Gene expressions profiling gut microbiota in different races of humans. Sci Rep 2016;6:23075.

5. Creanza N, Kolodny O, Feldman MN. Cultural evolutionary theory: how culture evolves and why it matters. Proc Natl Acad Sci USA 2017;114:7782-9.

6. Tooby J, Cosmides L. Psychological foundations of culture. In: Barkow J, Cosmides L, Tooby J, eds. The adapted mind. New York: Oxford University Press; 1992.

7. Buss DM. Evolutionary psychology: the new science of the mind. New York: Routledge; 2016.

8. Richerson PJ, Boyd R. Not by genes alone: how culture transformed human evolution. Chicago: University of Chicago Press; 2005.

9. Krebs JR. The gourmet ape: evolution and human food preferences. Am J Clin Nut 2009;90:707S-11.

10. Rozin P. Food and eating. In: Kitayama SH, Cohen D, eds. Handbook of cultural psychology. New York: Guilford Press; 2007.

11. Attran S, Medin D, Ross N. Evolution and devolution of knowledge: a tale of two biologies. J R Anthropol Inst 2004;10:395-420.

12. Santoro FR, Nascimento ALB, Soldati GT, et al. Evolutionary ethnobiology and cultural evolution: opportunities for research and dialog. J Ethnobiol Ethnomed 2018;14:1.

13. WHO. WHO Fact Sheet No: 311 (2015) - Overweight and obesity. Geneva, Switzerland: World Health Organization; 2015.

14. Krebs NF, Himes JH, Jacobson D, et al. Assessment of child and adolescent overweight and obesity. Pediatrics 2007; 120:193-228.

15. Caprio S, Daniels SR, Drewnowski A, et al. Influence of race, ethnicity, and culture on childhood obesity: implications for prevention and treatment. Diabetes Care 2008;31:2211-21.

16. Neel JV. Diabetes mellitus: a "thrifty" genotype rendered detrimental by "progress"? Am J Hum Genet 1962;14:353-62.

17. Li NP, van Vugt M, Colarelli SM. The evolutionary mismatch hypothesis: implications for psychological science. Curr Direct Psychol Sci 2018;27:38-44.

18. Tooby J, Cosmides L. On the universality of human nature and the uniqueness of the individual: the role of genetics and adaptation. J Personal 1990;58:16-67.

19. Tooby J, Cosmides L. The past explains the present: emotional adaptations and the structure of ancestral environments. Ethol Sociobiol 1990;11:375-424.

20. Laland KN, Brown GR. Sense and nonsense. Evolutionary per- spectives on human behaviour. 2nd ed. Oxford: Oxford University Press; 2011.

21. Odling-Smee FJ, Laland KN, Feldman MW. Niche construction: the neglected process in evolution. Monographs in population biology 37. Princeton: Princeton University Press; 2003.

22. Speakman JR. Evolutionary perspectives on the obesity epidemics: adaptive, maladaptive and neutral viewpoints. Ann Rev Nut 2013;33:289-317.

23. Speakman JR. Thrifty genes for obesity and diabetes, an attractive but flawed idea and an alternative scenario: the 'drifty gene' hypothesis. Int J Obes (Lond) 2008;32:1611-7.

24. Prentice AM, Hennig BJ, Fulford AJ. Evolutionary origins of the obesity epidemic: natural selection of thrifty genes or genetic drift following predation release? Int $\mathrm{J}$ Obes 2008;32:1607-10.

25. Sellayah D, Cagampang FR, Cox RD. On the evolutionary origins of obesity: a new hypothesis. Endocrinology 2014;155:1573-88.

26. Watve MG, Yajnik CS. Evolutionary origins of insulin resistance: a behavioral switch hypothesis. BMC Evol Biol 2007;7:61.

27. Genné-Bacon EA. Thinking evolutionarily about obesity. Yale J Biol Med 2014;87:99-112.

28. Gjonça A, Bobak M. Albanian paradox, another example of protective effect of Mediterranean lifestyle? Lancet 1997;350:1815-7.

29. Shapo L, Pomerleau J, McKee M, et al. Body weight patterns in a country in transition: a population based survey in Tirana City, Albania. Public Health Nutr 2003;6:471-7.

30. Çela L, Kraja B, Hoti K, et al. Lifestyle characteristics and gastroesophageal reflux disease: a population based study in Albania. Gastroenterol Res Pract 2013;2013:936792.

31. Bregu A, Toçi E, Muja $H$, et al. Diabetes prevalence in Albanian adult population. Alban Med J 2012;4:9-13.

32. Lacko M. Disparities in mortality rates of working-age population in eastern, central and western Europe - A comparative quantitative analysis. Danube: Law Econ Social Issues Rev 2016;7:193-213.

33. Spahija B, Qirjako G, Toçi E, et al. Socioeconomic and lifestyles determinants of obesity in a transitional southeast European population. Med Arch 2012;66:16-20.

34. McLaren L. Socioeconomic status and obesity. Epidemiol Rev 2007;29:29-48.

35. Hill Jo, Wyatt HR, Reed GW, Peters JC. Obesity and the environment: where do we go from here? Science 2003;299:853-5.

36. Papas MA, Alberg AJ, Ewing R, et al. The built environment and obesity. Epidemiol Rev 2007;29:129-43.

37. Hyska J, Mersini E, Mone I, Burazeri G. Prevalence and demographic correlates of overweight and obesity among children in a transitional southeastern European population. J Community Health 2014;39:828-34.

38. United Nations, Department of Economic and Social Affairs, Population Division. World urbanization prospect: the 2014 revision. Technical report. New York: United Nations; 2015.

39. Bell SL, Phoenix C, Lovell R, Wheeler BW. Green space, health and wellbeing: making space for individual agency. Heath Place 2018;30:287-92.

40. Ekkel ED, De Vries S. Nearby green space and human wealth: evaluating accessibility metrics. Landscape Urban Plan 2017; 157:214-20.

41. Wandl A. Comparing the landscape fragmentation and accessibility of green spaces in territories-in-between across Europe. Urban Plann 2017;2:25-44. 